\title{
Laboratory studies of the effects of reduced prey choice caused by Bt plants on a predatory insect
}

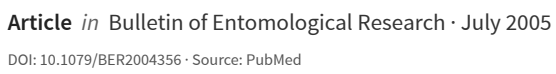

6 authors, including:

$$
\text { Guy M Poppy }
$$

SEE PROFILE

Ian Denholm

University of Hertfordshire

224 PUBLICATIONS 12,643 CITATIONS

SEE PROFILE

Some of the authors of this publication are also working on these related projects:

Sustainability assessment of agriculture and ecosystem services in England and Wales: an integrated systems approach View project

ASSETS (Attaining sustainable services from ecosystems through tradeoff scenarios) View project 


\title{
Laboratory studies of the effects of reduced prey choice caused by Bt plants on a predatory insect
}

\author{
T.H. Schuler ${ }^{1 *}$, A.J. Clark ${ }^{1}$, S.J. Clark ${ }^{2}$, G.M. Poppy ${ }^{3}$, \\ C.N. Stewart, $\mathrm{Jr}^{4}$ and I. Denholm ${ }^{1}$ \\ ${ }^{1}$ Plant and Invertebrate Ecology Division and ${ }^{2}$ Biomathematics Unit, \\ Rothamsted Research, Harpenden, AL5 2JQ, UK: ${ }^{3}$ Division of Biodiversity \\ and Ecology, School of Biological Sciences, University of Southampton, \\ Southampton, SO16 7PX, UK: ${ }^{4}$ Department of Plant Sciences, The \\ University of Tennessee, Knoxville, TN 37996, USA
}

\begin{abstract}
Crops transformed to express Bacillus thuringiensis (Bt) toxins can cause close to $100 \%$ mortality of certain target pest species. This study assessed the effect of target pest reduction on the predatory insect Chrysoperla carnea (Stephens) in the presence of alternative prey. Numbers of lacewings recovered from Bt oilseed rape (cultivar Oscar, event O52) did not differ significantly from numbers of lacewings recovered from conventional oilseed rape in cage experiments with the target pest Plutella xylostella (Linnaeus) and the non-target pest Myzus persicae (Sulzer) when aphid densities were high. However, significantly fewer lacewings were recovered from Bt plants as aphid densities were lowered. Lacewing weights were not affected by plant type.
\end{abstract}

Keywords: Transgenic plants, biosafety, Chrysoperla carnea, Myzus persicae, Plutella xylostella, Brassica napus

\section{Introduction}

Crops transformed to express toxins of Bacillus thuringiensis (Bt) can provide very high levels of control of certain target pest species (Carozzi \& Koziel, 1997; Obrycki et al., 2001). Natural enemies that specialize in attacking such target pests may experience local prey depletion in such crops but more generalist natural enemies may be less affected if sufficient alternative prey is present (Obrycki et al., 2001). The quantification of individual factors affecting interactions between plants, herbivores and predatory insects is made difficult in the field by the complexity of food webs, the variation introduced by changes in environmental conditions and the small size of the study organisms. Laboratory studies carried out in large cages can make a valuable contribution to investigating these effects as they

${ }^{*}$ Fax: +441582760981

E-mail: Tanja.Schuler@bbsrc.ac.uk allow a reduction in complexity and standardization of environmental conditions (Schuler et al., 2001).

The objectives of the present study were to investigate effects of target pest removal by a transgenic plant expressing a Bt toxin on a generalist predator in the presence of alternative prey, and to develop methodology for the risk assessment of transgenic plants. Laboratory experiments involved the predatory lacewing Chrysoperla carnea (Stephens) (Neuroptera: Chrysopidae) and transgenic oilseed rape, Brassica napus (Linnaeus) (Brassicaceae), expressing the Bt toxin Cry1Ac, which is highly toxic to larvae of the diamondback moth, Plutella xylostella (Linnaeus) (Lepidoptera: Plutellidae) but has no direct effect on aphids such as the peach-potato aphid, Myzus persicae (Sulzer) (Hemiptera: Aphididae) (Schuler et al., 2001, 2003).

\section{Materials and methods Experimental plants}

The Bt oilseed rape (B. napus cv. Oscar) transformation event 052 used for this study expressed a truncated 
synthetic Bt cry1Ac gene under the control of the 35S promoter (Stewart Jr. et al., 1996). Untransformed plants of the parent cultivar Oscar were used as controls. Plants were grown in 1 litre pots in a glasshouse set at $20^{\circ} \mathrm{C}$ and a minimum day length of $14 \mathrm{~h}$. Bt toxin concentrations in leaves were quantified with a commercial enzyme-linked immunosorbent assay (ELISA) kit (Agdia, Elkhart, USA) as described previously (Schuler et al., 2001). Plants were checked daily and any flower buds removed, as required by statutory biosafety rules.

\section{Insects}

A culture of P. xylostella (Philippine strain) that had been kept at Rothamsted for over ten years without exposure to Bt or other insecticides was maintained on oilseed rape plants at $22 \pm 3^{\circ} \mathrm{C}$ and a light:dark cycle of $16: 8 \mathrm{~h}$. A parthenogenetic culture of $M$. persicae (clone 1076A) was maintained on oilseed rape at $18 \pm 2^{\circ} \mathrm{C}$ and a light:dark cycle of $16: 8 \mathrm{~h}$. First instar C. carnea larvae were obtained from Koppert Biological Systems UK Ltd and used for experiments on the day of arrival. During transport, C. carnea larvae had been supplied with eggs of the moths Sitotroga cerealella (Olivier) (Lepidoptera: Gelechiidae) and Ephestia kuehniella Zeller (Lepidoptera: Pyralidae) as a food source.

\section{Experiments with two prey species in field simulator cages}

Four experiments were conducted, in which the availability of aphid prey to $C$. carnea larvae was gradually reduced. In the first two experiments plants were each infested with 30 apterous M. persicae adults. Experiments 3 and 4 were started with 15 and 8 apterous $M$. persicae adults per plant, respectively. All other parameters remained constant. Field simulator cages measuring $1.7 \mathrm{~m} \times 1.2 \mathrm{~m}$ $\times 1.0 \mathrm{~m}$ were used as described previously (Schuler et al., 2001). Four cages were used in each experiment and three transgenic plus three control plants were placed inside each cage. The plants in each cage formed two rows of three plants, transgenic plants always alternating with control plants. Each plant represented an independent replicate. Plants were 5-6 weeks old at the start of an experiment. Experiments were conducted using a light:dark regime of $16: 8 \mathrm{~h}$, a room temperature of $21 \pm 1^{\circ} \mathrm{C}$ (resulting in $26 \pm 4^{\circ} \mathrm{C}$ inside the cages) and ambient relative humidity conditions.

Aphids were allowed to reproduce for 11 days before 100 two- to three-day-old $P$. xylostella eggs were placed on each plant. Two days later 20 first instar lacewing larvae were placed on each plant. Plants did not touch each other and were placed in trays filled with water to prevent insects from moving between plants. The experiments were terminated nine days after release of lacewing larvae (just before $P$. xylostella adults emerged from their pupae) and numbers of insects per plant assessed. Lacewings recovered were flash frozen and then dried at $60^{\circ} \mathrm{C}$ for $48 \mathrm{~h}$ before dry weights were taken.

In each experiment, P. xylostella egg viability was assessed by monitoring the hatch rate of 300 to 400 surplus eggs of the same egg batch as used in the experiment. Hatch rates in the four experiments ranged between $89 \%$ and $98 \%$.

A preliminary experiment had shown that lacewing recovery rates were very low if no shelters for lacewings to hide and rest during the day were provided. To ensure a reasonable recovery rate of lacewing larvae in the present study, two corrugated cardboard shelters (each consisting of a piece measuring $8 \mathrm{~cm} \times 13 \mathrm{~cm}$ rolled up around a wooden stick) were inserted in each pot. In addition, two layers of filter paper $(24 \mathrm{~cm}$ diameter, with a hole cut in the centre for the plant stem) were placed around the base of each plant.

At the end of experiment 3, subsamples of aphids were collected from each plant, flash frozen and tested for the presence of Cry1Ac by ELISA as described above.

\section{Statistical analysis}

The numbers of $C$. carnea recovered from each of the Bt and non-transgenic plants (out of the initial 20 lacewings per plant) were compared using a generalized linear model with binomial error and logit link (logistic regression). When significant overdispersion was indicated, plant type differences were tested by comparing the ratio of the treatment and residual mean deviances against an F-distribution. Chrysoperla carnea mean dry weights were compared between plant types using analysis of variance with variability partitioned into that due to cages (blocks), plants (plots or replicates) within cages (treatment stratum in which plant type effects are estimated), and individual larvae (pseudoreplicates) on plants. ELISA test results for aphids (ng toxin per mg total protein) were analysed similarly. Correlation coefficients were used to describe relationships between numbers of $C$. carnea and $P$. xylostella (total numbers and pupae only) for both plant types together and for nontransgenic plants alone.

\section{Results}

No P. xylostella larvae or pupae were recovered from Bt plants. Some small feeding holes of first instar larvae were visible in leaves of Bt plants but no larger feeding holes were observed, indicating that no $P$. xylostella larvae survived past the first instar on these plants. Mean percentages of $P$. xylostella recovered (either as larvae or pupae) from nontransgenic plants were $39.5 \%, 34.1 \%, 43.8 \%$ and $29.9 \%$ for experiments 1-4, respectively (out of 100 P. xylostella eggs placed on each plant at the beginning of the experiment). Some dead P. xylostella larvae were observed in the water trays indicating that a proportion of larvae had tried to emigrate from the plant or had fallen off following disturbance.

Aphid densities in each of the four experiments increased to several thousand aphids per plant, but were too high and aphid distribution across different leaves of the plants too patchy for an accurate assessment of final aphid numbers. ELISA test results of aphids feeding on Bt plants did not differ significantly from those of aphids feeding on nontransformed plants $\left(\mathrm{F}_{1,19}=1.04, P=0.321\right)$, suggesting that aphids did not ingest Cry1Ac when feeding on Bt oilseed rape. The Bt plants from which the aphids were collected contained between $0.007 \%$ and $0.021 \%$ Bt toxin of total leaf protein.

Most $C$. carnea recovered were found sheltering under the filter paper collar, dry leaves, the rim of the plant pot or within the cardboard shelters. Some dead C. carnea larvae were observed in the water trays indicating that a proportion of lacewing larvae had attempted to leave the plants or had fallen off. The proportion of C. carnea recovered from plants varied with experiment and plant type (fig. 1). No effect of 


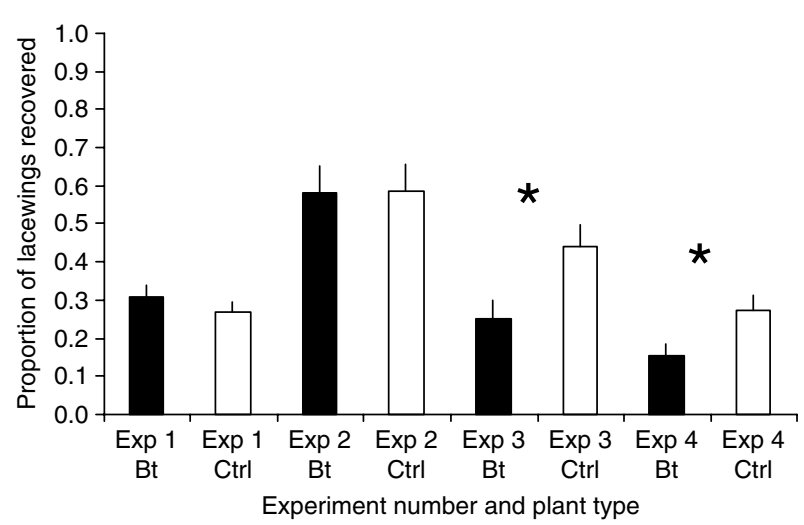

Fig. 1. Proportions of Chrysoperla carnea recovered at the end of four experiments. Twenty $C$. carnea were placed on each plant at the beginning of each experiment. Initial densities of Myzus persicae were 30 aphids per plant in experiments 1 and 2, 15 aphids per plant in experiment 3 and 8 aphids per plant in experiment 4. Each plant also received 100 Plutella xylostella eggs. Error bars represent standard errors based on the binomial distribution. An asterisk indicates a significant difference between $\mathrm{Bt}$ and non-transgenic control plants at $P<0.05$.

plant type on the numbers of lacewings recovered was observed in experiment $1\left(\chi^{2}{ }_{1}=1.03, P=0.311\right.$; fig. 1$)$. More lacewings were recovered in experiment 2 but again there was no significant difference between plant types $\left(F_{1,19}=0.00, P=0.967\right.$; fig. 1$)$. When the data sets of experiments 1 and 2 were combined for statistical analysis, there was no evidence of a significant effect of plant type on proportion of $C$. carnea recovered $\left(F_{1,39}=0.14, P=0.712\right)$. However, the proportion of $C$. carnea recovered in experiment 3, in which initial aphid densities were halved, was significantly lower on Bt plants compared to non-transgenic plants $\left(F_{1,19}=5.78, P=0.027\right.$; fig. 1$)$. In experiment 4 , in which initial aphid densities had been reduced even further, the proportion of lacewings recovered was again significantly lower on Bt plants compared to non-transgenic plants $\left(\mathrm{F}_{1,19}=5.14, P=0.035\right.$; fig. 1$)$.

No significant effect of plant type on final weights of C. carnea was observed in any of the four experiments (table 1 ). The majority of $C$. carnea were in their last larval instar (81-97\%) when the experiments were terminated.
Some (0-19\%) were still in the second larval instar and some (0-14\%) larvae had already spun a cocoon.

Numbers of $C$. carnea recovered were negatively correlated with total numbers of $P$. xylostella in experiment 1 but not experiment 2 or the combined analysis table 2 . There was a positive correlation between these two variables in experiments 3 and 4 (table 2). When the data from Bt plants were excluded, numbers of $C$. carnea recovered were negatively correlated with total numbers of $P$. xylostella recovered in experiments 1 and 2 but there was no statistically significant correlation between these two variables in experiments 3 and 4 (table 2).

Chrysoperla carnea numbers were negatively correlated with numbers of $P$. xylostella pupae in the combined analysis of the first two experiments (table 2). However, the correlation between these two variables was significantly positive in experiment 4 (table 2). Numbers of $C$. carnea per non-transgenic plant were negatively correlated with numbers of P. xylostella pupae in the combined analysis of the first two experiments but there was no statistically significant correlation between these two variables on non-transgenic plants in experiments 3 and 4 (table 2).

\section{Discussion}

Recovery rates and weight gain of $C$. carnea did not differ between $\mathrm{Bt}$ plants and non-transgenic plants in the two experiments that had the highest density of $M$. persicae (experiments 1 and 2). However, significantly fewer C. carnea were recovered from Bt plants compared to non-transgenic plants in experiments with lower aphid densities (experiments 3 and 4). For most of the duration of the experiments, the only prey available to lacewings on the Bt plants were aphids and other lacewings since none of the P. xylostella larvae appeared to have survived on Bt plants past their first instar. The high mortality of P. xylostella on Bt plants was as expected based on earlier studies with the same Bt plant line (Schuler et al., 2003). In contrast, on non-transgenic plants, lacewings had a choice between feeding on aphids, lacewings or moth larvae and pupae. As C. carnea larvae are cannibalistic, increased movement due to a more limited supply of aphid colonies may have resulted in higher lacewing mortality due to cannibalism. The differences in C. carnea recovery rates in the four experiments suggest that the 'removal' of $P$. xylostella by the Bt plant may only affect lacewings at low but not at high aphid populations.

Table 1. Dry weights of Chrysoperla carnea larvae recovered from Bt and non-transgenic control plants. The four experiments investigated the indirect effects of Bt plants on C. carnea at different densities of Myzus persicae.

\begin{tabular}{|c|c|c|c|c|c|c|c|}
\hline Experiment & Plant type & $\begin{array}{l}\text { Initial } \\
\text { aphid density } \\
\text { per plant }\end{array}$ & Mean (mg) & sem & $n$ & $F(d f)$ & $P$ \\
\hline 1 & $\mathrm{Bt}$ & 30 & 1.86 & 0.180 & 74 & $2.82(1,19)$ & 0.109 \\
\hline 2 & $\begin{array}{l}\text { Control } \\
\text { Bt }\end{array}$ & 30 & $\begin{array}{l}2.26 \\
2.95 \\
2.74\end{array}$ & $\begin{array}{l}0.194 \\
0.151 \\
0.151\end{array}$ & $\begin{array}{r}64 \\
140 \\
140\end{array}$ & $0.85(1,18)$ & 0.369 \\
\hline $\begin{array}{l}1 \text { and } 2 \\
\text { combined }\end{array}$ & $\mathrm{Bt}$ & 30 & 2.58 & 0.118 & 214 & $0.01(1,38)$ & 0.921 \\
\hline & Control & & 2.58 & 0.121 & 204 & & \\
\hline 3 & $\mathrm{Bt}$ & 15 & 2.70 & $\begin{array}{l}0.259 \\
0.197\end{array}$ & $\begin{array}{r}60 \\
103\end{array}$ & $1.73(1,18)$ & 0.205 \\
\hline 4 & $\begin{array}{l}\text { Bt } \\
\text { Control }\end{array}$ & 8 & $\begin{array}{l}2.87 \\
2.95\end{array}$ & $\begin{array}{l}0.224 \\
0.169\end{array}$ & $\begin{array}{l}37 \\
65\end{array}$ & $0.03(1,18)$ & 0.868 \\
\hline
\end{tabular}


Table 2. Correlations between numbers of Chrysoperla carnea and numbers of Plutella xylostella recovered per plant in four experiments differing in the initial density of Myzus persicae.

\begin{tabular}{|c|c|c|c|c|c|c|c|}
\hline \multirow[t]{2}{*}{ Plants } & \multirow[t]{2}{*}{ Experiment } & \multirow[t]{2}{*}{ Initial aphid density per plant } & \multirow[t]{2}{*}{$n$} & \multicolumn{2}{|c|}{$\begin{array}{l}\text { Total } P . x y l o s t e l l a \\
\text { recovered }\end{array}$} & \multicolumn{2}{|c|}{$\begin{array}{l}\text { P. xylostella pupae } \\
\text { recovered }\end{array}$} \\
\hline & & & & $\mathrm{r}$ & $P$ & $\mathrm{r}$ & $P$ \\
\hline \multirow{5}{*}{$\begin{array}{l}\text { Bt and } \\
\text { control plants }\end{array}$} & 1 & 30 & 24 & -0.429 & $*$ & -0.455 & * \\
\hline & 2 & 30 & 24 & -0.207 & ns & -0.085 & ns \\
\hline & $\begin{array}{l}1 \text { and } 2 \\
\text { combined }\end{array}$ & 30 & 48 & -0.223 & ns & -0.307 & $*$ \\
\hline & 3 & 15 & 24 & 0.412 & * & 0.378 & ns \\
\hline & 4 & 8 & 24 & 0.442 & $*$ & 0.430 & $*$ \\
\hline \multirow{5}{*}{$\begin{array}{l}\text { Control } \\
\text { plants only }\end{array}$} & 1 & 30 & 12 & -0.582 & * & -0.59 & * \\
\hline & 2 & 30 & 12 & -0.688 & * & -0.218 & ns \\
\hline & $\begin{array}{l}1 \text { and } 2 \\
\text { combined }\end{array}$ & 30 & 24 & -0.578 & $* *$ & -0.586 & $* *$ \\
\hline & 3 & 15 & 12 & -0.103 & ns & -0.195 & ns \\
\hline & 4 & 8 & 12 & 0.182 & ns & 0.317 & ns \\
\hline
\end{tabular}

${ }^{*} P<0.05 ;{ }^{* *} P<0.01 ;$ ns, $P>0.05$.

Previous studies have shown that larval mortality of C. carnea increased when larvae were fed the lepidopteran herbivore Spodoptera littoralis (Boisduval) (Lepidoptera: Noctuidae) reared on Bt maize expressing Cry1Ab but not when they were fed the aphid Rhopalosiphum padi Linnaeus (Hemiptera: Aphididae) or the spider mite Tetranychus urticae Koch (Acari: Tetranychidae) reared on the same Bt maize (Dutton et al., 2002; Hilbeck et al., 1998). In the present study, the lack of statistically significant differences between lacewing recovery rate or weight gain on Bt plants compared to non-transgenic plants in experiments 1 and 2 indicates that the lacewings were not directly affected by Cry1Ac expressed in the Bt plants used in the current study. In fact, it is probably unlikely that lacewings on Bt oilseed rape plants were exposed to Cry1Ac during the experiments. Although larvae of $P$. xylostella have chewing mouth parts and ingest leaf cells containing Cry1Ac, the P. xylostella larvae feeding on Bt plants died soon after hatching. It appears unlikely that small moribund neonate $P$. xylostella larvae would have represented a significant proportion of a lacewing's prey. Also, Bt-susceptible P. xylostella larvae consume only very limited amounts of Bt oilseed rape leaf tissue before death (Schuler et al., 2003). Aphids do feed and develop normally on Bt oilseed rape (Schuler et al., 2001) but the ELISA test results suggest that $M$. persicae did not ingest Bt toxin when feeding on Bt oilseed rape plants. Similar results have been reported for aphids of the genus Rhopalosiphum on Bt maize (Head et al., 2001; Raps et al., 2001). Aphids have sucking mouthparts and feed predominantly on phloem sap. Bt toxins may therefore not be present in the phloem of $\mathrm{Bt}$ maize and $\mathrm{Bt}$ oilseed rape.

When attacked by natural enemies, $P$. xylostella larvae often exhibit a violent thrashing behaviour (Schuler, unpublished observations). They also frequently try to escape natural enemy attack by spinning a silk thread and letting themselves drop off the plant (Potting et al., 1999). A previous study assessing the preference of $C$. carnea for aphid and moth larvae in choice tests with $R$. padi and $S$. littoralis reported that lacewing larvae preferred to feed on R. padi (Meier \& Hilbeck, 2001). Lacewings in the present study may therefore have preferentially attacked aphids rather than $P$. xylostella larvae.
Numbers of lacewings and total numbers of $P$. xylostella were significantly negatively correlated on non-transgenic plants in the first two experiments, suggesting a significant impact of lacewings on the P. xylostella population, either through predation or through disturbance. However, why the correlation was only significant at the higher aphid densities and not at the lower aphid densities remains unclear.

Pupae of P. xylostella became available as prey on nontransgenic plants during the last few days of each experiment as $P$. xylostella larvae reached maturity. Lacewings were repeatedly found feeding on $P$. xylostella pupae. Since $P$. xylostella pupae are similar in size to fully grown lacewing larvae and are unable to escape or physically defend themselves, they appear to be low risk-high return prey for C. carnea.

Large numbers of aphids were not only observed in experiments 1 and 2 but also at the termination of experiments 3 and 4 , indicating that even in the latter experiments the lacewings were not able to detect or reach and consume all aphid colonies on a plant. The reduced recovery rates of lacewings on Bt plants in experiments 3 and 4 may have been partly due to prey being more dispersed, requiring more lacewing movement and increasing the chances of the predators encountering each other.

The differences in lacewing recovery rates observed in the present study could be due to either lower lacewing survival or changes in predator behaviour that increased lacewing dispersal. Waxy leaf surfaces of Brassica species are more difficult for lacewings to adhere to and walk on than glossy leaf surfaces (Eigenbrode et al., 1999). Lacewings have been reported to avoid walking on lower leaf surfaces of plants with waxy leaves (Eigenbrode et al., 1999). One explanation for differences in lacewing recovery rates observed in the present study may be that as aphid numbers were reduced lacewings did not find enough prey on the upper leaf surfaces and more lacewings fell off the plants while trying to reach prey on the lower leaf surfaces; an effect that may well have been more pronounced on $\mathrm{Bt}$ plants than control plants due to the absence of $P$. xylostella larvae on Bt plants.

The present study demonstrates that prey reduction through Bt plants may affect predatory insects negatively 
even at relatively high densities of alternative prey. However, the results also suggest the presence of more complex density-dependent behavioural herbivore-herbivore and herbivore-predator interactions.

\section{Acknowledgements}

Funding from the Department of the Environment, Food and Rural Affairs (Defra) of the UK supported this work. Rothamsted Research receives grant-aided support from the Biotechnology and Biological Sciences Research Council of the UK.

\section{References}

Carozzi, N.B. \& Koziel, M.G. (1997) Advances in insect control: the role of transgenic plants. London, Taylor \& Francis.

Dutton, A., Klein, H., Romeis, J. \& Bigler, F. (2002) Uptake of Bt-toxin by herbivores feeding on transgenic maize and consequences for the predator Chrysoperla carnea. Ecological Entomology 27, 441-447.

Eigenbrode, S.D., Kabalo, N.N. \& Stoner, K.A. (1999) Predation, behavior, and attachment by Chrysoperla plorabunda larvae on Brassica oleracea with different surface waxblooms. Entomologia Experimentalis et Applicata 90, 225-235.

Head, G., Brown, C.R., Groth, M.E. \& Duan, J.J. (2001) Cry1Ab protein levels in phytophagous insects feeding on transgenic corn: implications for secondary exposure risk assessment. Entomologia Experimentalis et Applicata 99, $37-45$.

Hilbeck, A., Baumgartner, M., Fried, P.M. \& Bigler, F. (1998) Effects of transgenic Bacillus thuringiensis corn-fed prey on mortality and development time of immature Chrysoperla carnea (Neuroptera: Chrysopidae). Environmental Entomology 27, 480-487.
Meier, M.S. \& Hilbeck, A. (2001) Influence of transgenic Bacillus thuringiensis corn-fed prey on prey preference of immature Chrysoperla carnea (Neuroptera: Chrysopidae). Basic and Applied Ecology 2, 35-44.

Obrycki, J.J., Losey, E.J., Taylor, O.R. \& Jesse, L.C.H. (2001) Transgenic insecticidal corn: beyond insecticidal toxicity to ecological complexity. Bioscience 51, 353-361.

Potting, R.P.J., Poppy, G.M. \& Schuler, T.H. (1999) The role of volatiles from cruciferous plants and pre-flight experience in the foraging behaviour of the specialist parasitoid Cotesia plutellae. Entomologia Experimentalis et Applicata 93, 87-95.

Raps, A., Kehr, J., Gugerli, P., Moar, W.J., Bigler, F. \& Hilbeck, A. (2001) Detection of Cry1 Ab in phloem sap of Bacillus thuringiensis corn and in the non-target herbivores Rhopalosiphum padi (Homoptera: Aphidae) and Spodoptera littoralis (Lepidoptera: Noctuidae). Molecular Ecology 10, 525-533.

Schuler, T.H., Denholm, I., Jouanin, L., Clark, S.J., Clark, A.J. \& Poppy, G.M. (2001) Population-scale laboratory studies of the effect of transgenic plants on non-target insects. Molecular Ecology 10, 1845-1853.

Schuler, T.H., Potting, R.P.J., Denholm, I., Clark, S.J., Clark, A.J., Stewart, Jr. C.N. \& Poppy, G.M. (2003) Tritrophic choice experiments with Bt plants, the diamondback moth (Plutella xylostella) and the parasitoid Cotesia plutellae. Transgenic Research 12, 351-361.

Stewart, Jr. C.N., Adang, M.J., All, J.N., Raymer, P.L., Ramachandran, S. \& Parrott, W.A. (1996) Insect control and dosage effects in transgenic canola containing a synthetic Bacillus thuringiensis cryIAc gene. Plant Physiology 112, 115-120. 
